\title{
The Use of the USSBV Model as a Mechanism for Training in a Learning Factory
}

\author{
Vusumuzi Malele, Khumbulani Mpofu, and Mammo Muchie
}

\begin{abstract}
Entrepreneurial and innovative engineers that are needed by industry either as employers or employees emanate from the universities. However, literature emphasises that there is a need for closing the gap between students' university studies and industry expectation because most students are simply a liability during the early phases of their career life. To bridge such a gap, students should be trained to solve the real world problems using a systematic, integrative approach such as the University-Sponsored Student Business Venture (USSBV) model. The latter should take place in the non-lecturer dominated environment which foster interdisciplinary and hands-on learning approach that provides students with life-long experiences. This paper presents a case of how the USSBV model could be used in a Learning Factory (LF) as the didactic method for training students to gain the flair of entrepreneurship and innovation. The aim of the training would be for students to apply their theoretical content to a real working environment to experience or establish new ventures that could solve industrial and societal problems. For example, the train safety and ergonomics problems present an opportunity on how the USSBV model could be used to train students in the LF and thereby, give students opportunities of generating ideas as solutions for the problem and be equipped at commercializing those ideas. In this regard, the application of the USSBV model in the LF results in project-based learning and non-lecturer dominated learning environment that source ideas directly from the industry/society. This will develop and enhance students' technical and soft skills (i.e. collaboration, communication, presentation, and critical thinking).
\end{abstract}

Index Terms - Entrepreneurship and innovation, learning factory, non-lecturer environment, open innovation model.

\section{INTRODUCTION}

Everyday industrial and system engineering work involves a wide range of activities. Industrial Engineering (IE) draws upon knowledge and skill in the mathematical, physical, business, and social sciences. It combines this knowledge and skills with the principles and methods of engineering analysis and design, to specify, predict, and evaluate the results to design, produce, improve and install integrated systems of people, information and infrastructure.

Due to its interdisciplinary and multidisciplinary approach to produce engineering solutions, IE prepares students to be employed in various sectors (i.e. banking, insurance, forestry, manufacturing, management, construction, mines, education, etc). With its flair for inventing new things, IE also prepares students to engage in entrepreneurship and innovation. Entrepreneurship and innovation allow students to employ

Manuscript received April 12, 2018; revised June 28, 2018.

The authors are with Tshwane University of Technology (TUT), South Africa (e-mail: Vusi.Malele@dst.gov.za). themselves and others; thereby, aid in reducing the level of unemployment. It also allows universities to operate in four core functions, namely: (i) research and development (development of knowledge), (ii) teaching and learning (the transfer of knowledge), (iii) community engagement (the application and consumption of knowledge), and (iv) entrepreneurship and innovation (the application and exploitation of knowledge).

The preceding brief discussion points out to the fact that IE would need analytical people with an aptitude for mathematics, science, and business who enjoys working with other people. However, the authors observed that there is a lack of much-needed aptitude in most university students which mainly affect their skills than knowledge. This means most university graduates obtain their degrees and diplomas with good knowledge but fewer practical skills that prepare them for industry or either as employers or employees. Research has shown that doing while learning or active learning is better than the normal traditional way of teaching a student without showing or guiding them in practical ways [1]. This has a potential of graduating entrepreneurial and innovative engineers.

It is this paper's hypothetical view that students could be oriented to the expectations of entrepreneurship and innovation from the very early stages of their studies thereby increasing the probability of them becoming self-employed. In this regard, in the university context, such an orientation should happen beyond the classroom but in an interactive and productive environment which is aligned with industry and business expectations.

Entrepreneurial and innovative engineers that are needed by industry either as employers or employees emanate from the universities. However, literature emphasises that there is a need for closing the gap between students' university studies and industry expectation. To bridge such gap students should be trained in a non-lecturer dominated environment such as the learning factory, to solve the real world problems using a systematic, integrative approach such as the University-Sponsored Student Business Venture (USSBV) model. Literature has described such an environment as the Learning Factory (LF).

Except for this introduction, this paper will present a problem statement and the main research question that guided this paper, then briefly discuss the LF concept and environment. It will further discuss how a university-sponsored student business venture (USSBV) model could be used in the LF environment to promote the entrepreneurship and innovation as a mechanism towards self-employment. It would be concluded by providing necessary recommendations and framework for future 
studies.

\section{PRoblem StATEMENT}

Upon employing university graduates, industry finds that some of them are still raw and unproductive during the early period of their careers [2]. Some of the graduates receive a cultural shock from the work environment in the industry. They are simply a liability during the early phases of their careers, which at times deters some industries from promptly engaging university graduates upon exiting the university. Industry at times goes an extra mile to train them so that they reach a level on which they would be productive. However, not all industries are forthcoming to take up this burden. They would rather employ an experienced person than newly graduated university students.

As the way to redeem such a problem, literature [1][2][3][4] indicate that universities in some partnership with industry established the LF which is an environment that could enhance students' competencies and provide them with the necessary skills for the industry either as employers or employees. The LF could also afford students the chance to become more productive and open-minded for lifelong learning.

At the Department of Industrial Engineering, Faculty of Engineering and Built Environment, Tshwane University of Technology a plan has been set-up to establish an LF environment with the main goal of helping students to close the technical and engineering entrepreneurial skills gap. This will happen under the auspices of a Research Chair in Manufacturing and Skills Development funded TUT and in partnership with the Gibela Rail Transport Consortium (Gibela),

It is envisaged that training would be done in partnership with strategic partnerships to provide practical experience to aspiring technicians, technologist, engineers and engineering technology-based entrepreneurs.

The TUT/Gibela LF is envisaged to have two pillars: (i) business (rail rapid) incubation, and (ii) the technology development. The rail rapid incubator is proposed to be a place where the training and development of business skills for university students and community business members could take place. It is envisaging that through the incubator, students and technology-based business community members will experience a real working environment where they can apply theoretical content to solve complex industry problems. By applying this technique students visiting the LF would be able to adapt quickly to the technical work environment.

It follows that there exists a need for different didactical approaches that could aid TUT/Gibela's LF to achieve its main goals in particular that of providing students with the necessary business skills.

One such didactical approach is to use the USSBV model proposed by [5] to provide the students with an experience of a real working environment where they could apply their theoretical content to establish ventures that could solve industrial and societal problems. These ventures would provide a form of employment to students.

\section{LEARNING FACTORY}

The phrase learning factory is made up of two terms (i) learning and (ii) factory. According to [3] learning as a term emphasize the importance of experiential learning where research has shown that learning by doing leads to greater retention and application possibilities as opposed to teaching or traditional methods.

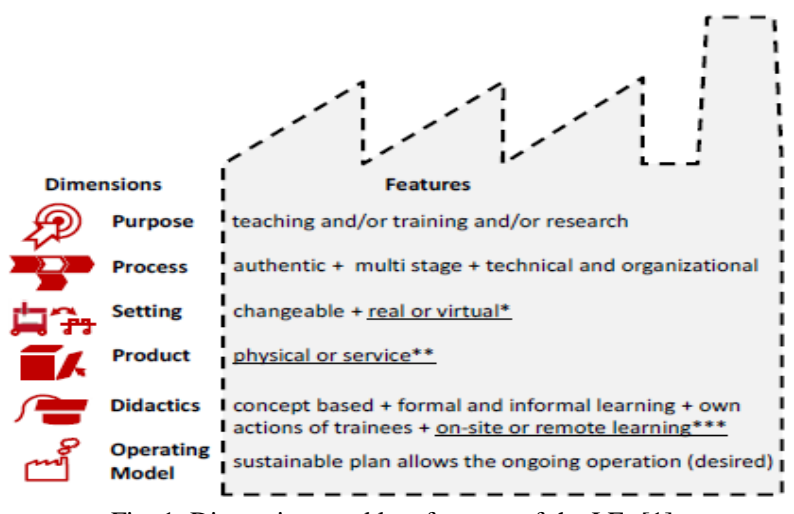

Fig. 1. Dimensions and key features of the LFs [1]

In this paper, learning refers to the process of knowledge gaining through practical or theoretical means, where students are considered as the knowledge receivers. Factory refers to the production environment where practical activities are performed based on industry standards.

This paper views the LF as an environment within the university that would allow students to solve challenges emanating from industry and society through practical activities that aim at contributing a prototype/product/services. In this regard, the LF laboratories differ from the traditional, highly focused, disciplinary laboratories that are tied to specific courses because students would experience a product and the related manufacturing and/or assembly process [3].

The LF is a production-technological learning environment [4]. It provides a reality-conform production environment as a learning environment where only minor abstractions are possible in relation to the industry [1]. This is possible because LFs integrate different teaching methods with the objective of moving the teaching-learning processes closer to real industrial problems using different dimensions (see Fig. 1).

The LF supports the idea that its concepts could also be applied in the education sector with a purpose of creating an environment where students would be oriented and also perform some tasks that would help them in future career paths as well as developing personal skills and build strong confidence in the workplace.

In this regard, using dimensions and key features depicted in Fig. 1, LF covers a wide variety of learning environments which are action-oriented in approach with participants acquiring competencies through structured self-learning processes [1], [4].

Learning Factories have been used for educational purposes, research and training in areas such as manufacturing, energy efficiency, service operations and processes [6]. Furthermore, LF could help develop entrepreneurship and innovation among students. Universities 
could create and adopt different teaching methods to improve students' skills to produce highly qualified problem solvers, with hands-on experience, career guidance, etc. In this regard, this paper suggests the use of a USSBV model as a didactic mechanism for providing students with entrepreneurship and innovation hands-on experience.

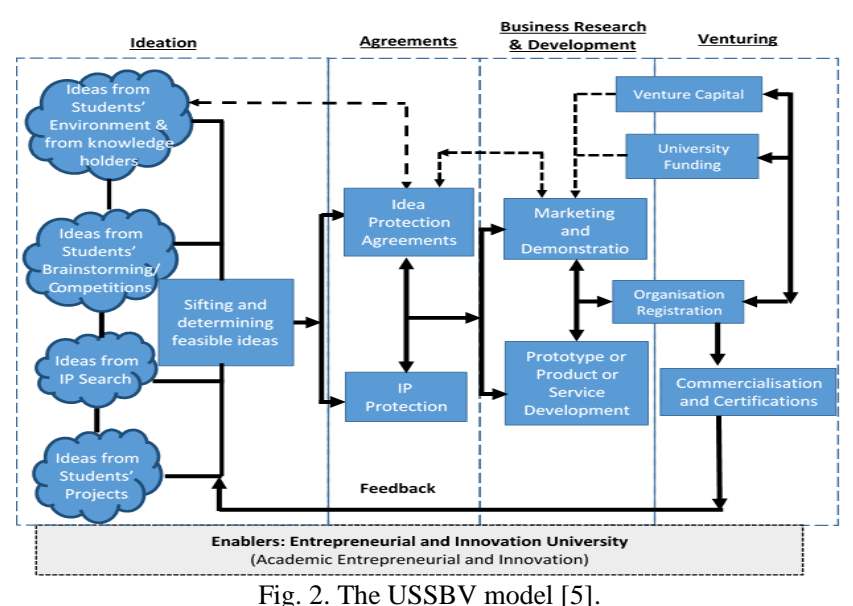

\section{THE UNIVERSITY-SPONSORED STUDENT BUSINESS VENTURE (USSBV) MODEL}

Students exposure to entrepreneurship and innovation is of particular importance because it could facilitate the chances of students' establishing business ventures as the methods of self-employment [7]. One key way of helping students to have a creative mind of entrepreneurs or innovators is by introducing them to the concepts of entrepreneurship and innovation through the Entrepreneurship and Innovation Education (EIE).

The EIE is an interactive process seeking to determine feasible ideas that could be exploited for establishing business enterprises. It supports a non-lecturer dominated learning environment which promotes the development of creativity, innovativeness and capability for self-directed lifelong learning in students [8].

The EIE involves students in the exercise of searching for needs and problems in their environment, and thereby finding appropriate solutions or applying and developing known solutions to the identified problem. Cooper and Edgett [9] provide 18 different methods that could be used to conduct Ideation; while, [10] used the EIE process to illustrate where the Ideation task would essentially take place, and brainstorming is used as an activity used to conduct it. Almost all of the EIE models begin with an idea generation stage also called Ideation.

The USSBV is an open hybrid-agile EIE model or a new venture creation model used to inculcate the culture of entrepreneurship and innovation to students through training them on how to produce either a prototype or product or service which could be used to establish new business ventures. It comprises of four main stages (as depicted in Fig. 2) namely: (i) Ideation stage, (ii) agreement stage, (iii) business research and development, and (iv) venture creation stage. It also comprises of two pseudo-stages: (i) the feedback loop and the enabler.
The USSBV Ideation stage is used to create awareness about the different sources of the idea that students could utilise to solve challenges that they have identified. The ideation stage is driven by the existing needs. The input to Ideation is either industrial or societal challenges that exist within the students' environment. These enable the students to use different techniques to source ideas towards a solution for the specific problem. However, the idea could be a specific problem but yield a solution for another.

Both these solutions could be exploited further as business ideas. In the USSBV ideas emanate from different sources, i.e. research and development, patent search, students' intuitiveness (i.e. brainstorming sessions, normal creativity, etc).

Depending on the type of the solution that is intended and also the feasible ideas towards that solution, in the USSBV those ideas are protected. This is achieved through the Agreement or Intellectual Property Rights (IPR) stage which uses different types of protection agreements, i.e. patent registration, memorandum of understanding (MoU), memorandum of agreement (MoA), non-disclosure agreements, terms of reference, etc. For example, to protect all parties, in a case whereby students obtain ideas from community members like in rural areas, an agreement between the student, the community member and university should be signed.

The Business Research and development (R\&D) stage follows the agreement stage and seeks to determine if the agreed upon idea could be developed further or send directly to the market. It allows the students to use the university enablers (i.e. policies, assets and resources) to develop prototypes or products or services.

These prototypes/products/services are then marketed and demonstrated (or vice-versa) to the: (i) selected target market (i.e. those who suggested ideas and solution was conceptualise for, or selected group which marketing research identified as potential buyers), and (ii) entire potential market (i.e. expansion of buyers). Based on the kind of outputs (i.e. prototypes/products/services) that this stage could illustrate a need for university funding or a venture capital funding and could be needed. The results of this stage foster the begin of the venture creation stage.

The venture stage is used to formulate a strategic new venture or an organisation that would be used to market the outputs of the USSBV exercises. The initial members of the new venture would be students as founders, the university or venture capital as sponsors, and community as the market. For example, sponsors are needed because other entrepreneurship and innovation activities could be necessary for further marketing, salaries of new employees, etc. This stage produces more ideas that are feedback, mostly to the Ideation stage. However, depending on how they are conceptualised, they could be routed to any stage for further development and exploitation.

\section{DISCUSSION}

The same concept of the USSBV could be used to inculcated students with the flair of entrepreneurship and 
innovation with a purpose of aiding them to establish their own businesses. The USSBV could be adopted in the LF as the training model because its processes map directly to the LF's dimensions (see Fig. 3).

In the case of the TUT/Gibela LF environment, the USSBV model could be used to emphasise active or action-oriented entrepreneurship and innovation teaching and learning, which could be supported by practical or project-based learning. This allows integration of real business issues into the classroom via authentic problems which come directly from industry or society, and are implemented through actions that to mirror the industry/society that raised them.

To illustrate the use of USSBV in an LF, consider the human factors in the manufacturing of a passenger train. The human factor theory supports a user-centric design. In this regard, it cannot be disassociated with the concept of safety and ergonomics of either the Loco pilot (train driver) or passengers of the commuter railway train.

From the viewpoint of the ergonomics, a train driver's working place and the passenger seating with all relevant characteristics represent an important element to be considered in the train planning process as well as during its operation [11]. For example, the work of a train driver takes place in the train's cab which the interior should be designed in such way that an appropriate level of safety, efficiency and comfort of the driver's work is assured. Furthermore, just like for the train driver, the passengers should also be able to obtain all necessary safety and comfort including reliable and efficiently working train equipment.

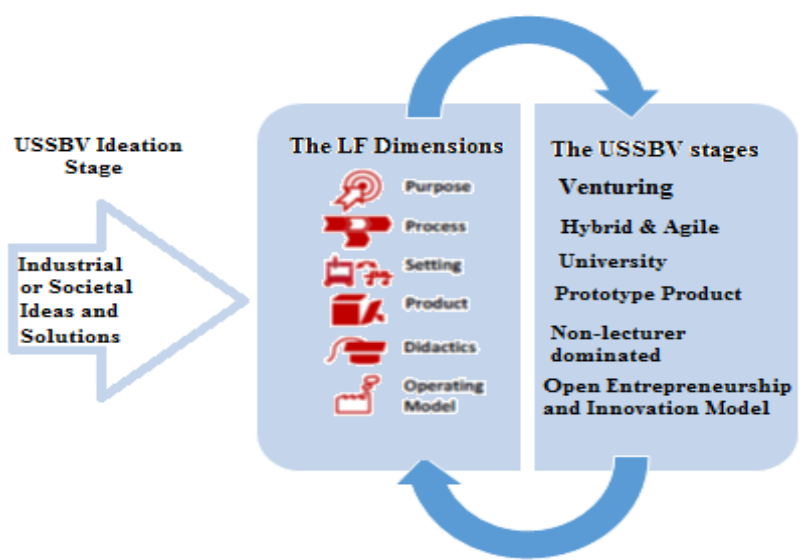

Fig. 3. The USSBV stages incorporated in the LF.

In this case, consider the LF purpose dimension of training and teaching students how to design a suitable air conditioning system for both the loco pilot (train driver) and the passengers. The USSBV process stage relating to such a dimension would be to allow students to conduct ideation (idea generation) tasks with an aim of establishing new ventures that would supply the market with innovative solutions for the train air condition system. For example, the students would have to interact with the train drivers and passenger to obtain their ideas regarding what would best suit them.

Then, students would have to use available components and/or design new components using hybrid and agile methods to and supply such components.

Students new designed components might yield prototypes or some new product services that could commercialize. In this regard, the USSBV advocates that the university place a business or intellectual property officer within the LF to facilitate the commercialization of components.

The latter would not be conducted and dominated by the facilitated but would be driven by the curiosity and entrepreneurial intent of the students. Hence, the didactics would not be lecturer dominated but student action learning which is the form of learning through practice and a means of problem-solving in the real life [12].

The USSBV model advocates for action-oriented learning and problem based learning as highlighted above because its concept emphasized on learning by doing with minimal lecturers'/facilitators guidance, while students offer services in practice and experience working procedure that would seamless link them with future career [11]-[14].

\section{CONCLUSION}

A more practice-oriented teaching and learning are necessary. The LF has a potential of enabling different paths of training for students. As illustrated above, the USSBV would allow students within the LF to first identify the different challenges that seek solutions; secondly, source and brainstorm feasible ideas that could be a potential solution(s). These ideas would then be protected, researched for business purposes, be funded and a venture (with the student/s as the major shareholder) be established to exploit the ideas either as prototype or product or service.

This paper proposes that the use of USSBV model in the LF would allow project-based learning to develop and enhance students' technical and soft skills (i.e. collaboration, communication, presentation, and critical thinking).

Furthermore, the USSBV model has a potential of developing new research agenda in different areas. For example, studies of assessing the students' attitudes, perceptions, characteristics and biases on entrepreneurship and innovation hands-on learning could be investigated. The types and funding of start-up ventures that students suggest could be investigated. In this regard, the USSBV model is a good model to be incorporated into the LF environment.

Against such a backdrop, this paper recommends that different institution should establish LF and use didactics that embrace action-oriented learning and problem-based learning.

\section{ACKNOWLEDGEMENTS}

Our thanks to TUT, Gibela, DST and NRF for supporting this work.

\section{REFERENCES}

[1] E. Abele, J. Metternich, M. Tisch, G. Chryssolouris, W. Sihn, H. ElMaraghy, V. Hummel, and F. Ranz, "Learning factories for research, education, and training," in Proc. the $5^{\text {th }}$ Conference on Learning Factories, Procedia - ScienceDirect, vol. 32, pp. 1-6, 2015.

[2] A. Merwe, V. Hummel, and S. Matope, "The learning factory: A didactic platform for knowledge transfer in South Africa," presented at International Conference on Competitive Manufacturing (COMA '16), January 27-29, 2016, Stellenbosch, Stellenbosch University, South Africa. 
[3] D. T. Matt, E. Rauch, and P. Dallasega, "Variety management in manufacturing. Mini-factory - A learning factory concept for students and small-medium sized enterprises," in Proc. the $47^{\text {th }}$ CIRP Conference on Manufacturing Systems, vol. 17, pp. 178-183, 2014.

[4] M. Tisch, C. Hertle, J. Cachay, E. Abele, J. Metternicha, and R. Tenbergb, "A systematic approach on developing action-oriented, competency-based learning factories," in Proc. the 46 CIRP Conference on Manufacturing Systems, SciVerse ScienceDirect, vol. 7 , pp. 580-585, 2013.

[5] V. Malele, K. Mpofu, and M. Muchie, "A university-sponsored Student business venture model for bridging the entrepreneurial and innovation chasm," in Proc. the $1^{\text {st }}$ International Conference on Entrepreneurship Development (ICED), Central University of Technology, Bloemfontein, South Africa, April 5-7, 2017.

[6] F. Baenaa, A. Guarin, J. Moraa, J., Sauzab, and S. Retat, "Learning factory: The path to industry 4.0," in Proc. the $7^{\text {th }}$ Conference on Learning Factories, Procedia - ScienceDirect, vol. 9, pp. 73-80, 2017.

[7] V. Malele, K. Mpofu, and M. Muchie, "Lesson learned from exposing computer systems engineering students to entrepreneurship and innovation activities," in Proc. the $4^{\text {th }}$ Biennial Conference of the South African Society for Engineering Education (SASEE), Central University of Technology, Bloemfontein, South Africa, pp. 146-171, June 14-15, 2017,

[8] K. Moyle, "Building innovation: Learning with technologies," Australian Education Review, Australian Council for Educational Research (ACER) Press, 2010.

[9] R. G. Cooper and S. J. Edgett, "Ideation for product innovation: What are the best methods?" Product Development \& Management Association (PDMA) Visions Magazine, vol. 32, no. 1, 2008.

[10] G. Thorsteinsson and T. Page, "A virtual reality learning environment to improve ideation: An icelandic action research project," Pedagogika, vol. 91, 2008.

[11] M. Žnidarič, P. Jenček, and J. Kolenc, "Ergonomic analysis of train driver workplace at train ICS pendolino series 310," in Proc. the $14^{\text {th }}$ International Conference on Transport Science, Slovenia: Potoroz, 2011.

[12] C. L. Moses, A. M. Oluwafunmilayo, M. A. Olokundun, and A. M. Gbenga, "Entrepreneurship education and action-oriented pedagogical approaches," International Journal of Educational Science and Research (IJESR), vol. 5, no. 5, pp. 53-60, 2015.

[13] P. Chung, R. C. Yeh, and Y.-C. Chen, "Influence of problem-based learning strategy on enhancing student's industrial oriented competences learned: an action research on learning weblog analysis," International Journal of Technology and Design Education, vol. 6, pp 285-307, 2016.
[14] C.-Y. Yung, T.-Y, Chang, and C.-L, Hsieh, “Applying action-oriented learning approach on campus practicum," Journal of Tourism and Hospitality, vol. 6, p. 271, 2017.

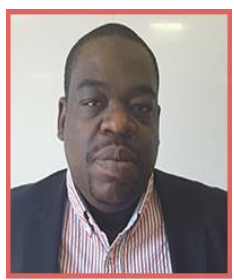

Vusumuzi "Vusi" Malele holds a master of engineering science (MEngSci) in electronics from the Stellenbosch University. He is currently a doctora candidate, enrolled for a doctor of technology (DTech) degree in industrial engineering at Tshwane University of Technology (TUT). His research interest is on: leadership and strategic management entrepreneurship and innovation management, engineering and technology management, information and communication technology (ICTs), and skills development.

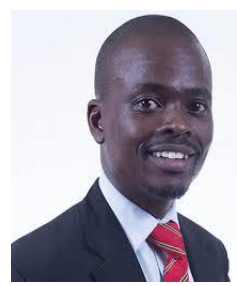

Khumbulani Mpofu holds a doctor of technology (DTech) degree in mechanical engineering from Tshwane University of Technology (TUT). He is a head of the Department for Industrial Engineering, and a professor of manufacturing systems at TUT. He is a rated research and a TUT/Gibela research professor of manufacturing skills development. His research includes fuzzy theory, knowledge systems,

reconfigurable manufacturing, robot technology, computer integrated manufacturing and innovation management. His research results are influential in South Africa and have been published in international journals.

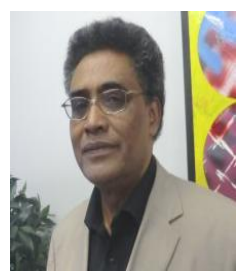

Mammo Muchie holds a doctor of philosophy (DPhil) degree in science, technology, and innovation for development (STI4D) from the University of Sussex. He is a rated research professor and currently a DST/NRF research professor of innovation studies at the Tshwane University of Technology. He is the founder and chief editor of the African Journal of Science, Technology, Innovation and Development that has been founded in 2009. (www.ajstid.com). He is also an editor of: The Ethiopian Electronic Journal for Research \& Innovation Foresight (Ee-JRIF) (www.nesglobal.org/eejrif); Globelics Journal of Innovation and Development (published by Routledge) (www.globelics.org), and the Journal of Agriculture and Economic Development. Prof. Muchie has widely published, since 1985, he has produced over 365 publications, including books, chapters in books, and articles in internationally accredited journals and entries in institutional publications. 